\title{
Host Language Proficiency, Intercultural Sensitivity, and Study Abroad
}

\section{Jane Jackson}

The Chinese University of Hong Kong

\section{Introduction}

The number of foreign language students who join study abroad programs continues to increase annually, especially those who take part in shortterm sojourns lasting eight weeks or less (Donnelly-Smith, 2009; Institute of International Education 2009; Spencer and Tuma, 2008). What can be accomplished in such a short stay in the host culture? Is it possible for sojourners to enhance their proficiency in the host language and simultaneously develop their ability to communicate appropriately in intercultural encounters in the host culture? Does the developmental sequence of intercultural competence parallel that of linguistic competence, as suggested by Bennett, Bennett \& Allen (2003)? What steps can be taken to maximize the language and cultural learning of short-term sojourners?

This paper focuses on a case study of advanced foreign language students who took part in a short-term study abroad program. By examining their journeys, from their home environment to the host culture and back again, we gain a deeper understanding of the development of their intercultural communicative competence. In the process, the linkage between linguistic and intercultural development is problematized. While the participants were Hong Kong university students who sojourned in England, elements of their stories should reach across ethnic, linguistic, and geographic lines and resonate with foreign language learners in other parts of the world.

\section{Developmental Model of Intercultural Sensitivity (DMIS)}

The Developmental Model of Intercultural Sensitivity (DMIS), which was developed by Bennett (1993) to explain the acquisition of intercultural competence, provided the conceptual framework for the study. Based on the observed and reported experiences of people in intercultural encounters, it centers on the constructs of ethnocentricism and ethnorelativism (Bennett 1993, 1997; Bennett \& Bennett, 2004; Landis, Bennett \& Bennett, 2004). 
In the former, "the worldview of one's own culture is central to all reality" (Bennett, 1993: 30), whereas the latter is linked to "being comfortable with many standards and customs and to having an ability to adapt behavior and judgments to a variety of interpersonal settings" (p. 26). In the DMIS, intercultural sensitivity is thought to involve personal and cognitive growth and the emergence of "a mindset capable of understanding from within and from without both one's own culture and other cultures" (Bennett et al., 2003: 252). Further, consistent with contemporary critical, poststructuralist perspectives (e.g., Guilherme, 2002; Jackson, 2008; Pavlenko \& Lantolf, 2000), in this model, identity is viewed as relational and dynamic, rather than static and unitary.

More specifically, the DMIS theorizes that individuals move from ethnocentric stages (Denial, Defense, and Minimization), through ethnorelative stages of development (Acceptance, Adaptation, and Integration) as they acquire intercultural competence. People, however, do not necessarily follow a linear progression (e.g., advancing to the next stage in sequence). Due to unpleasant intercultural experiences or acute culture shock, for example, they may retreat to a lower level of sensitivity.

The DMIS is based on the premise that ethnorelative worldviews are more effective in fostering the attitudes, knowledge, and behavior that facilitate successful intercultural communication and adjustment in unfamiliar cultural settings (Kim, 2001, 2005). This intercultural competence is defined by Bennett and Bennett (2004) as "the ability to communicate effectively in cross-cultural situations and to relate appropriately in a variety of cultural contexts" (p. 149). While the DMIS offers study abroad researchers a theorybased explanation of sojourner competence in intercultural encounters, it does not specifically address host language proficiency.

More recently, efforts have been made to extend the DMIS to link foreign/second language learning with intercultural development. Bennett et al. (2003) speculate that there is a "typical fit between language proficiency levels and developmental levels of intercultural sensitivity" (p. 255). They speculate that learners who have an advanced level of proficiency in the target language are apt to be in an ethnorelative stage of cultural development (e.g., adaptation/ integration), whereas those who are less proficient are likely to possess an ethnocentric mindset (e.g., denial/ defense). These hypotheses were scrutinized in my study of advanced foreign language sojourners.

\section{Empirical research on intercultural competence and study abroad}

The DMIS has served as the theoretical basis for the investigation of 
intercultural competence in such diverse populations as second or foreign language learners, pre-service or in-service teachers, teacher educators, student sojourners, healthcare professionals, missionaries, and international aid workers. In the following studies the Intercultural Development Inventory (IDI) (Hammer and Bennett, 2002) was used to determine the relative intercultural sensitivity of student sojourners, as defined by the DMIS.

Using a mixed-method approach, Medina (2008) assessed the intercultural sensitivity of 28 American university students who participated in one of two study abroad language programs: 18 attended a 7-week program in Taxco, Mexico and 10 took part in a 16-week sojourn in Mexico City. By the end of their stay, the longer-term sojourners demonstrated a more sophisticated understanding and awareness of nuances in the host culture (e.g., discourse, politics), than those with less time abroad. Interestingly, the IDI revealed that the participants had inflated opinions about their degree of intercultural sensitivity, rating it at least one stage higher than their actual level.

In France, Engle and Engle (2004) investigated the French language learning and intercultural sensitivity of American sojourners who were participating in either a semester or full-year-abroad program. The longerterm sojourners made significantly more progress in cultural understanding and intercultural communicative competence, with the greatest advances in their IDI scores occurring in the second half of their stay. The IDI was also used by Anderson, Lawton, Rexeisen, and Hubbard (2006) to measure the impact of a short-term study abroad program on the intercultural awareness and sensitivity of 23 American business students in Europe. As a group, the sojourners lessened their ethnocentric tendencies and became more willing to accept and adapt to cultural differences. The researchers concluded that welldesigned short-term programs have the potential to foster the development of intercultural competence in student sojourners.

The studies described above investigated the intercultural sensitivity development of American students on sojourns ranging from 7 weeks to a year. Would an investigation of Hong Kong sojourners in England yield similar findings? Is a 5-week stay in the host culture sufficient to enhance the intercultural communication skills, understanding, and sensitivity of advanced foreign language sojourners? In the following case study, I consider the extent to which the DMIS accounts for their intercultural learning. In the process, I explore the accuracy of Bennett et al.'s (2003) hypothesized linkage between second language proficiency and intercultural sensitivity. 


\section{The Special English Stream: A short-term study abroad program for English majors}

In 2001, in line with the Chinese University's internationalization aims, the English Department established the Special English Stream (SES), a study abroad program designed to enhance the English language proficiency, intercultural sensitivity, literary awareness, and intercultural communicative competence of English majors. In particular, it aimed to foster their sociopragmatic awareness, which Thomas (1984) defines as knowledge of how language is affected by social and cultural features in a particular context. The program encourages the participants to become more confident when communicating in English in a variety of contexts, including informal, social situations.

The SES consists of pre-sojourn seminars in applied linguistics (ethnographic research), intercultural communication (culture-general/ culture-specific elements) and English literature; a 5-week sojourn in England; post-sojourn debriefing sessions; and an undergraduate dissertation related to the experience abroad. The sojourn includes a homestay component, literary and cultural studies at a university in central England, excursions (e.g., to the theatre, museums), and small-scale ethnographic projects (Jackson, 2006). A unique feature of the SES is that all elements are credit-bearing and integrated into the Bachelor of Arts program of studies. For most cohorts, the sojourn component has been subsidized by a University grant.

\section{The Study}

\section{Research design and aims}

To better understand the language and cultural development of the cohort that is the focus of this article, I adopted a mixed-method case study approach. For more than a year, I had the opportunity to spend time with the students in both informal and formal situations; this afforded me the opportunity to observe their language and intercultural development. This study differed from earlier ethnographic investigations of SES groups (Jackson, 2008), in that I also employed a quantitative instrument (the IDI) to provide an objective measure of the participants' cultural sensitivity at strategic intervals.

\section{The group profile}

The SES cohort under study was comprised of thirteen (12 females and 1 male) full-time English majors in the second year of a three-year BA program. On entry into the SES, the students had an average age of 20.2 years and a grade point average of 3.3. All of them grew up in Hong Kong and spoke 
Cantonese as their first language. Seven also spoke Putonghua (Mandarin) as an additional language; 2 were familiar with a Mainland Chinese dialect (the mother tongue of one of their parents); and 3 spoke basic French. All of the students had an advanced level of proficiency in English with an average of 'B' on the 'Use of English' A-level exam at the end of their secondary schooling. Before the sojourn, one female student (S5), who spoke Cantonese, Putonghua, French, and English, had participated in two study abroad programs: a yearlong exchange program at an English-medium university in Canada and a short-term French immersion program in France. Another female student (S6) had joined secondary school classmates on a 3-week tour of Australia. The travel experiences of the remainder of the group had largely consisted of short family trips to Mainland China or organized tours to other Asian countries.

Before becoming a member of the SES, none of the participants had ever taken a course in intercultural or cross-cultural communication, anti-racist education, or multiculturalism. Further, except for the student who had spent a year in Canada, their use of English had largely been restricted to academic settings in Hong Kong. Most had had very limited exposure to informal, social English before traveling to England. Only a few had personal relationships with culturally (or ethnically) dissimilar others.

All of the participants signed a consent form as part of the home institution's research ethics review procedures. The students were assured that their participation (or non-participation) would not affect their grades. Although free to withdraw at any time, none did.

\section{Instrumentation}

\section{Qualitative measures}

Pre-sojourn qualitative data included: an application letter to join the SES, a language and cultural identity narrative, an intercultural reflections journal, open-ended surveys, and an interview that prompted the participants to reflect on: their cultural background, language use, identity, previous travels/ study abroad experiences, intercultural contact, and aspirations/ concerns about the impending trip to England. During this phase I kept detailed field notes.

As well as my field notes, qualitative data collected during the sojourn included a diary and weekly open-ended surveys designed to draw out student views about: their intercultural adjustment, their awareness and reactions to cultural differences, their use of English in daily life, their identities, their perception of their intercultural communication skills and sensitivity; and their investigations of a cultural scene. Data about the students' intercultural adjustment and behavior was also gathered from their instructors/ homestay co-coordinator at the host institution. 
Post-sojourn qualitative data included: an open-ended survey, an interview with the participants about their sojourn and re-entry experiences. In particular, the interviewees were encouraged to reflect on the impact of study abroad on: their intercultural awareness and sensitivity, self-conception, and intercultural communication skills. During a 3-month period, I supervised the development of the ethnographic dissertation of those who chose this option. This afforded me the opportunity to have further informal conversations with them about their sojourn and re-entry experiences. I continued to keep field notes during this phase of the study.

\section{Quantitative data}

I employed the Intercultural Development Inventory (IDI) (Hammer, 2009; Hammer \& Bennett, 2002; Hammer, Bennett \& Wiseman, 2003) to measure the participants' intercultural sensitivity/ worldview orientation to cultural difference as conceptualized in the DMIS. This psychometric instrument has demonstrated construct validity and reliability (Hammer, 2009; Hammer et al., 2003; Paige, Jacobs-Cassuto, Yershova \& DeJaeghere, 2003) and, as was noted in the literature review, is widely used in study abroad research.

Respondents to the IDI rate their agreement or disagreement to 50 statements using a 5-point Likert scale. The analysis of their choices reveals their Developmental Orientation (DO), that is, their primary orientation toward cultural differences and commonalities (Hammer 2009). As well as measuring overall intercultural sensitivity, the IDI results yield scores for 5 subscales (Denial, Polarization: Defense/Reversal, Minimization, Acceptance, Adaptation) (Hammer, 2009). Denial measures a worldview that simplifies and/or avoids cultural difference. Polarization: Defensel Reversal measures a judgmental orientation that views cultural differences in terms of "us" and "them". In Defense, "us" is uncritically viewed as superior, whereas in Reversal (R), the opposite bias prevails. Minimization (M) measures a transitional worldview that emphasizes cultural commonality and universal values. With limited cultural self-awareness, individuals in this phase may not pay sufficient attention to cultural differences. Acceptance measures a worldview that can comprehend and appreciate complex cultural differences, while Adaptation identifies the capacity to alter one's cultural perspective and adapt one's behavior so that it is appropriate in a particular cultural context.

Besides computing the respondents' Developmental Orientation (DO), the IDI measures their Perceived Orientation (PO), that is, their perception of their own intercultural sensitivity and ability (Hammer, 2009; Hammer \& Bennett, 2002; Paige et al., 2003). A gap between the DO and PO of higher 
than seven points is considered a meaningful difference.

\section{Procedures and analysis}

Once the students had agreed to participate, I set up a project database in NVivo (Bazeley, 2007; Richards, 2009), a qualitative software program. Each piece of data was entered into the database soon after it was gathered, resulting in a rich database of oral and written narratives, digital images, and IDI scores. Using an "open coding" approach (Charmaz, 2006; Grbich, 2007), I devised codes to reflect what I saw in the material rather than restrict myself to preconceived ideas. New categories continually emerged, while others were reorganized as I acquired a deeper understanding of the relationship between items. By triangulating data types and sources, I aimed to discover how the students perceived cultural differences and made sense of their intercultural experiences in both Hong Kong and England. Since all of the data was dated, I was able to link their oral and written narratives with the three administrations of the IDI. This helped me to track their level of intercultural sensitivity and sociopragmatic awareness throughout the program.

\section{Findings}

With the help of NVivo, data for the full group has been analyzed and cases of individual participants are being developed to better understand their language and cultural learning and identity reconstruction over time. The triangulated data revealed that a complex range of individual characteristics (e.g., personality attributes, adaptive stress management, degree of openness to cultural difference, motivation, attitudes, previous study abroad) and environmental factors (e.g., degree of host receptivity, quality of host-sojourner interaction, access to communities of practice in the host culture) affected sojourn learning. Although in the same short-term study abroad program, these differences led to variations in the cultural, intellectual, linguistic, and personal development of the participants.

The scope of this paper is largely limited to a discussion of intercultural sensitivity and sociopragmatic awareness, and, due to space limitations, only a small sample of the narrative data is provided. Efforts have been made to include representative quotations at various stages of the program.

Table 1 presents the IDI profiles of the participants: on entry into the SES, after the 3-month pre-sojourn preparation, and immediately after the 5-week sojourn in England. These scores provide an indication of each student's worldview development and position on the DMIS' ethnocentric/ ethnorelative continuum at these strategic points in time. The right hand columns of the chart also indicate whether or not the participants made 
progress in their intercultural sensitivity over time by comparing their preand post- IDI scores (Developmental Orientation and Perceived Orientation) at two junctures: after the pre-sojourn preparation and post-sojourn.

To better illustrate the development of their intercultural sensitivity over time and not lose sight of individual trajectories, the remainder of the paper focuses on six of the participants. Excerpts from their oral and written narratives are presented and linked to their IDI scores at three different intervals: on entry, after the pre-sojourn preparation; and after the sojourn. Their voices offer a window into their awareness of cultural differences and reactions to them as they progressed through the program. The selected individuals represent a range of IDI scores and trajectories: S7 had advanced to a higher (ethnorelative) band level by the end of the program; S5 and S12 made progress throughout the program but remained in the same band level; S3 moved to a higher band level but regressed slightly after the sojourn; S2 and S10 advanced after the pre-sojourn preparation but regressed to a lower band after spending 5 weeks in the host culture.

\section{On entry into the SES}

The pre-sojourn narrative data (application letter, pre-sojourn interview, first few entries in the intercultural reflections journal, pre-sojourn survey) offered insight into the students' level of intercultural sensitivity on entry into the program and was generally in accord with the IDI scores. Similar to the previous SES cohort (Jackson, 2010), the first administration revealed that all of the students possessed inflated opinions about the level of their own intercultural sensitivity. Except for S3, all of the students believed they were in either Acceptance or Adaptation; in many cases, this was considerably higher than their Developmental Orientation (DO).

The following excerpts from the NVivo database illustrate the intercultural sensitivity level of the selected students when they first joined the program:

\section{Denial}

On entry, S3 displayed the highest level of ethnocentricism in the cohort according to the IDI. Early on, she appeared to have little interest in learning more about cultural differences and, in the following excerpt, which was written in the first month of the intercultural communications course, she disclosed a preference for familiar "ways of being":

I think it is perfectly okay to do things in our ways because that's the way we are. (intercultural reflections journal, S3) (DO: Denial 62.37;

PO: Minimization 110.07) (italics in original) 


\section{Polarization: Defense/ Reversal}

At the beginning of the study, S2 was in the Polarization: Defense/ Reversal stage of development. In her narratives, she displayed a tendency to regard another culture as superior while frequently maligning her own. In the following excerpt, this young woman praised Japanese behavior and denigrated elements of Hong Kong culture:

From the historical point of view, Japan was once the enemy of China.

Yet, their team spirit and loyalty towards their own country are much better than ours. We, Hong Kongers, can learn many things from them. I really admire the Japanese today. (cultural identity narrative, S2) (DO: Polarization: Defense/ Reversal 77.73; PO: Acceptance 115.75)

\section{Minimization}

Among the selected participants, S7 and S12 were in Minimization when they joined the program. Both women trivialized cultural differences and emphasized that all human beings are basically the same.

I don't think it's really helpful to talk about differences across cultures. After all, I think people everywhere are pretty much the same. (presojourn interview, S7) (DO: Minimization 88.69; PO: Acceptance 119.61)

To maintain a harmonious relationship with someone from another culture, I think we just need to be ourselves. If we are friendly and kind and polite, that should be enough. (intercultural reflections journal,

S12) (DO: Minimization 89.33; PO: Acceptance 120.03)

As they viewed elements of their cultural world as universal, S7 and S12 did not see the need to make adjustments to enhance their communication with people from another cultural background.

\section{Acceptance}

When the program began, only 2 members of the group (S5, S10) possessed an ethnorelative worldview or "intercultural mindset", according to the IDI. S5 had already experienced two positive sojourns abroad (an academic year in Canada and a summer in France). By contrast, S10, the only male student in the group, had never traveled outside Asia. An empathetic listener, he had well developed interpersonal communication skills and was often sought out for advice by his peers. Although his intercultural contact had been limited, he was keen to experience another country and live with a host family. 
The attitude of these two individuals was markedly different from those who were in a more ethnocentric, monocultural stage of development. Both welcomed exposure to other ways of life and appreciated the opportunities that the knowledge of an international language accorded them. S5 appeared to have benefited from previous forays abroad. In their pre-sojourn interview and narratives, she and S10 expressed the desire to further enhance their intercultural communicative competence.

As cliché as it may sound, one of the benefits of my exchange in Canada is that I got to meet people from different cultures. Being a bilingual speaker allows me to move across cultures and experience a new way of life. (intercultural reflections journal, S5) (DO: Acceptance 117.33; PO: Adaptation 130.63)

Since high school I developed my passion to study English. It was because my dream is to travel around the world especially in Western countries and experience different cultures so as to enrich my knowledge and deepen the understanding of myself... Not only will the SES help me cultivate a deeper intercultural understanding, it will also let me attain higher English proficiency. (application letter to SES, S10) (DO: Acceptance 121.79; PO: Adaptation 130.80)

Interestingly, while their actual IDI scores placed them in the Acceptance range, both S5 and S10 believed that they were in the Adaptation stage of development. Similar to their peers, they overestimated their level of intercultural sensitivity, although to a lesser extent than most.

\section{After intensive pre-sojourn preparation}

The students' narratives (e.g., last entries in their intercultural reflections journal, pre-sojourn surveys administered just prior to departure for England) generally supported the levels of the DMIS that were indicated in the second presojourn administration of the IDI. The students still had inflated perceptions of their intercultural sensitivity, rating themselves, on average, in the Acceptance or Adaptation ranges. After the pre-sojourn preparation, according to the IDI, 9 of the 13 participants developed a higher level of intercultural sensitivity; however, most remained in the same band level, especially those who were in Minimization on entry. Among the selected individuals, S3 moved into Polarization: Defense/Reversal, S2 progressed to Minimization; S7 and S12 remained in Minimization, and S5 and S10 advanced within the Acceptance range. 


\section{Polarization: Defense/ Reversal}

S3 had become more aware of cultural differences and a bit less fearful of interacting with people from other cultures. As the following excerpt shows, she had started to see limitations in her self-professed "in-group" (Chinese Hong Kongers) and had begun to extol the virtues of Mainland Chinese. According to the DMIS, she still possessed an ethnocentric worldview as she employed dualistic "we-they" thinking and stereotyping.

I always used to think that Mainland Chinese, even college students, must be really backward and have poor proficiency in English. But I found myself so naïve because I've discovered that many students from the mainland speak very good English, much better than mine. Spending time with a Shanghaiese girl has made me realize how much more sophisticated and hard working they are compared to us Hong Kongers. (intercultural reflections journal, S3) (DO: Polarization: Defense/ Reversal 71.81; PO: Minimization 113.17)

\section{Minimization}

After participating in the intensive 14 -week pre-sojourn preparation, 10 of the 13 students (including S2, S7, and S12) were in Minimization, a more tolerant or transitional phase of development. The tendency of these individuals to view the world in terms of "us versus them," where us is superior, had lessened but was still present. As they still considered their communication style (e.g., degree of self-disclosure) as universal, they did not understand or appreciate the potential benefits of making adjustments to enhance intercultural relations.

When communicating with my friends, I don't speak out my feeling too honestly as my friends would not be happy about that. Instead, I try to express my feelings in an indirect way. I think this is also a good way to communicate with friends from other cultures. (intercultural reflections journal, S2) (DO: Minimization 93.16; PO: Acceptance 122.75)

I have figured out the one who blindly and cruelly judges others as weird is me... There is no excuse for making definite and superficial evaluations of others. One cannot and should not, be stuck in her or his own mindset and keep on crying out 'you are weird!' to the world outside. One should take the control to get rid of this mental confinement. We should realize that we're all pretty much the same underneath. (intercultural reflections journal, S12) (DO: Minimization 100.75; PO: Acceptance 125.83) 
Intercultural relationships are no different from the friendships with people from the same culture, in a sense that there are some essential elements in forming any kind of relationships... For instance, friends should open up themselves to share what they know, what they feel and what they think with each other honestly and sincerely. (intercultural reflections journal, S7) (Actual IDI score: Minimization 112.33;

Perceived score: Acceptance 129.62)

\section{Acceptance}

After the intensive pre-sojourn preparation there were still only 2 participants in the Acceptance phase, the same individuals who had been in this phase on entry. Both S5 and S10 had become more appreciative of cultural differences and similarities in behavior and values. In their narratives, they continued to display acceptance, respect, and appreciation of other worldviews and behaviors.

I think the world would be a much, much better, safer place if people responded to differences and conflicts with flexibility, tolerance, and respect. This attitude would definitely enable people to treat others with equality. Recognizing, appreciating, respecting, and embracing others means treating them with dignity and justice, which is what makes all of us valuable beings in this world. (intercultural reflections journal, S5) (DO: Acceptance 121.86; PO: Adaptation 134.02)

The intercultural communications course is helping me appreciate people who have a different way of life from me. My way of thinking is becoming more and more open and I think I respect others more. (intercultural reflections journal, S10) (DO: Acceptance: 122.77; PO: Adaptation 131.67)

\section{After the sojourn}

The post-sojourn administration of the IDI revealed that the students continued to have significantly inflated opinions about the levels of their own intercultural sensitivity, perceiving themselves to be in the Acceptance or Adaptation ranges. In many cases, their Perceived Orientation (PO) was well beyond their actual level of development (DO). Statements made by the participants (in their sojourn diary, weekly surveys, and post-sojourn interview) provided further insight into their intercultural adjustment and sensitivity during their stay in England and were generally in line with their actual IDI scores. 


\section{Polarization: Defense/ Reversal}

Post-sojourn, two students (S2 and S3) were in the Polarization: Defense/ Reversal phase of development. On entry into the SES, S2 had been in this phase but after three months of pre-sojourn preparation she had moved into the transitional phase, Minimization. By the end of the sojourn, however, she had regressed to her former stage of development, a more ethnocentric position. By contrast, S3 had been in the Denial phase on entry and had progressed to Polarization: Defense/ Reversal after the pre-sojourn preparation. She remained in this ethnocentric phase after the sojourn.

I think TV programs in Hong Kong are really poor but the BBC in Britain is so informative! Even the comedies have a satirical meaning. The quality of TV programs is much, much better there. Also, in Britain, cars let you cross the road but in Hong Kong, they would just crash into you! The British are much more polite than Hong Kongers. (post-sojourn interview, S3) Actual IDI score: Polarization: Defense/ Reversal 70.59; Perceived score: Minimization 113.70)

English people often regarded me as Japanese. I felt proud of this as Japan has a good reputation. Actually, the Japanese have much better behavior than Chinese. (post-sojourn interview, S2) (Actual IDI score: Polarization: Defense/ Reversal 72.61; Perceived score: Acceptance 115.77)

During her stay in England, S2 had become much more critical of Hong Kong "ways of being" and rejected a Hong Konger identity. Similar to S3, her comments revealed that she was still engaged in "us" vs. "them" thinking, which according to the DMIS, is indicative of an ethnocentric, monocultural stage of development.

\section{Minimization}

After 5 weeks in an English-speaking environment, 10 members of the group were in Minimization, the transitional phase of development, including S12 who remained in this phase throughout and S10 who had regressed from the Acceptance orientation. Both S12 and S10 downplayed the importance of intercultural communication skills to build relationships across cultures, believing that people were "basically the same."

My daily habits were like those of the local people. I did not find anything difficult to adjust to in daily life. Life was quite routine and stable there. Nothing different really. Things in England are pretty much like here. (post-sojourn interview, S10) (DO: Minimization 
107.90; PO: Acceptance 126.10)

The whole Warwickshire and England are now familiar to me. I'm glad that we've seen different aspects of England. English people are really just like ordinary Hong Kongers. (last sojourn survey, S12) (DO: Minimization 109.80; PO: Acceptance 127.23)

While S10 and S12 displayed more sociopragmatic awareness than those in the lower IDI band levels, they were still less sensitive to nuances in their hosts' discourse than those who were in Acceptance at this juncture. For example, they did not recognize that offers of tea in their homestay were an expression of hospitality and often an overture to engage in "small talk". Consequently, opportunities for intercultural relationship building were lost.

\section{Acceptance}

By the end of the sojourn, 2 members of the cohort were in the Acceptance stage. S5, the young woman with previous study abroad experience, had remained in this band level throughout the program. By contrast, S7 began her journey in Minimization, stayed in this phase after the pre-sojourn preparation, and advanced to Acceptance after the sojourn. By cultivating an "intercultural mindset", these young women were better able to recognize and appreciate cultural differences beyond the surface level. I observed that both demonstrated an effort to refrain from making snap, critical judgments about cultural practices that were new to them:

In Birmingham, there were many black people including bus drivers. Sometimes I asked them for directions and they were nice and willing to help. Before I really thought that they were inferior and had racial discrimination in my mind. But I don't have this perception anymore. Now, I just want to learn more about their culture by talking to them. (post-sojourn interview, S7 (DO: Acceptance 115.63; PO: Adaptation 131.14)

I'm glad that I have had the opportunity to explore myself in this program. It has stimulated me to reflect and confront myself in both personal and social levels. I'm now more self-aware and better able to enjoy and accept differences in other cultures. (post-sojourn survey, S5) (DO: Acceptance 121.87; PO: Adaptation 132.23)

At this juncture, the IDI scores and narratives revealed that both S7 and S5 possessed a better grasp of the complexity of cultures than their peers. I also discovered that they still had inflated perceptions of their level of intercultural sensitivity. 


\section{Discussion and conclusions}

The findings of the case study generally supported the primary assumption that underpins the DMIS. As the participants developed a "more complex and sophisticated" understanding of cultural differences, their intercultural competence grew (Intercultural Communication Institute, 2004). The oral and written narratives of those in the Acceptance stage, according to the IDI, revealed that they were more sensitive to cultural differences than their peers, going beyond superficial observations of visible phenomenon. In the host culture they noticed differing norms of behavior (e.g., discourse markers of politeness) and displayed more awareness of values and beliefs motivating practices that were unfamiliar to them.

Instead of rejecting anything new as "weird" or "annoying", those with a more ethnorelative orientation made an effort to find out what lay behind these practices. With a more flexible, open mindset they were willing to try novel "ways of being" (e.g., sometimes experimenting with local expressions) as they immersed themselves in homestay life. By developing closer ties with their host families, they gained more exposure to the host language and culture. Gradually, they displayed a higher level of sociopragmatic awareness and intercultural sensitivity and became more at ease and confident communicating in the host language in informal, social situations.

This small-scale study provides some evidence that the relationship between language and culture learning is more complex than what is hypothesized by Bennett et al. (2003). The developmental sequence of intercultural competence does not necessarily parallel linguistic competence. This is especially true when foreign language students are primarily exposed to academic discourse in a formal classroom situation and have little contact with people outside their "in-group". While all of the participants in this study had an "advanced" level of (academic) proficiency in the host language when they entered the study abroad program, the intercultural sensitivity of most lagged far behind. Prior to the sojourn in England, nearly all had very limited intercultural contact and were minimally aware of, or uncomfortable with values and modes of behavior (e.g., communication styles) that differed from their own. My study has reinforced the observation of Kramsch (1998), Byram (1997), Park (2006) and other applied linguists who maintain that it is naive to assume that intercultural competence will develop at the same rate as foreign language proficiency. As noted by Durocher (2007), "studying a foreign language does not, in and of itself, cure ethnocentricism and make students ethnorelative" (p. 155).

It is also important to be aware that students may significantly overestimate their level of intercultural sensitivity. This was apparent in 
Medina's (2008) study of American sojourners in Mexico and my current and previous investigations of Hong Kong sojourners in England (Jackson, 2010). In fact, some of my students perceived their intercultural competence to be several IDI band levels above their actual developmental level. Their inflated self-perception may have curtailed their drive to enhance their intercultural communication skills, especially during the pre-sojourn phase when they had limited contact across cultures.

Why might students inflate their personal perceptions of their level of intercultural sensitivity? Is there a plausible explanation for disparate actual and perceived IDI ratings? Fischer, Greitemeyer, and Frey (2007) offer some insight. These psychologists reviewed relevant research and found that people inflate self-assessments of their abilities for a multitude of reasons: the desire to save face and maintain positive self-esteem (e.g., Kruger, 1999; Taylor \& Brown, 1988, 1994), selective encoding (Kunda, 1990), and biased reference points (Ditto \& Lopez, 1992). Further, Kruger and Dunning (1999) maintain that individuals who lack knowledge and expertise in a particular domain may simply not be aware of their incompetence. This may then lead to inflated selfperceptions and limited motivation to change. On a more encouraging note, these researchers also discovered that enhancing the metacognitive awareness of participants can be beneficial. It can help them recognize limitations in their knowledge and skills, and, with adequate guidance and encouragement, they are then better positioned to set realistic targets for improvement.

In the present study, those with an ethnocentric worldview were not as attuned to host norms of politeness and gaps in their intercultural communicative competence. Their metacognitive awareness was not yet as well developed as that of their more ethnorelative peers. With limited intercultural knowledge and experience, they assumed that they were more interculturally sensitive than they actually were. In particular, they were unaware that their language choices and style of communication (e.g., limited self-disclosure, indirect discourse) might be impeding intercultural relations in that context.

Foreign language learners may have a reasonably good grasp of grammar and academic vocabulary but have little understanding of (or need for) the sociopragmatic dimension of the target language until they engage in sustained intercultural interaction either at home or abroad. This has important implications for the preparation and on-going support of foreign language learners who join study abroad programs. Explicit intercultural teaching should be incorporated into pre-sojourn programming. In particular, foreign language educators and interculturalists can design and facilitate activities that help learners develop the sociopragmatic awareness, cultural knowledge, communication skills, coping strategies and attitudes that can lead to more 
successful intercultural contact and adjustment. With this in mind, educators with a dual interest in language and cultural learning have offered valuable pedagogical advice to enhance the pre-sojourn learning of foreign language students and promote intercultural citizenship (e.g., Alred, Byram, and Fleming, 2003; Byram, 2008; Byram, Gribkova and Starkey, 2002, Bennett, 2009; Bennett, 1997; Bennett et al., 2003; Jackson, 2008, 2010; Paige, Cohen, Kappler, Chi, and Lassegard, 2006).

A well-designed intercultural communication course, in particular, can help students make sense of their study abroad experience and become more mindful in intercultural interactions whether at home or abroad. By linking theory with practice, students can be prompted to reflect more deeply on such issues as their communication style; the acculturation process; effective language and culture learning strategies; expectations and realistic goals for stays abroad; identity development and change; and preparation for reentry. For those who will reside in a homestay, the orientation could stimulate discussion on the roles and responsibilities of hosts and "guests", as well as creative and constructive ways to enhance host-sojourner communication. As they prepare for the challenges of adjusting to another culture, students can discover more about themselves and the host culture.

The development of intercultural communicative competence is a challenging process that merits attention before, during, and after a sojourn. There are no guarantees that simply being present in the host environment will bring about interculturality. In fact, in some cases, as previous researchers have found, it may have the opposite effect when students are ill-prepared. Without effective coping strategies, culture shock may endure and negative stereotypes may become further entrenched. Unfortunately, many institutions of higher education are still offering inadequate pre-sojourn preparation for the students they send abroad, largely ignoring barriers that may hinder the learning process (e.g., high levels of ethnocentricism, lack of knowledge of social discourse norms/ practices in the host culture, weak coping mechanisms to deal with the natural ups and downs of the adjustment process).

Foreign language educators, interculturalists, and study abroad researchers all have important roles to play to maximize the language and cultural development of student sojourners. Through well-designed and sequenced pre-sojourn, sojourn, and re-entry programming, this small-scale study suggests that it is possible to cultivate higher levels of intercultural sensitivity and sociopragmatic awareness in students, including those who take part in short-term sojourns. In this globalized, interconnected world, intercultural competence is as vital as foreign language competence and it is simply naïve to assume that they will develop automatically and simultaneously. As educators, 
we have the responsibility to develop appropriate curricula and strategies to help foreign language students become competent, sensitive global citizens and professionals.

\section{Acknowledgments}

This study was funded by a Direct Grant from The Chinese University of Hong Kong (Ref. no. 2010312), with additional support from the Research Council of Hong Kong (General Research Fund Ref. no. CUHK444709). I would like to express my sincerest gratitude to the student sojourners. Without their co-operation and candor this research would not have been possible.

\section{References}

Alred, G., Byram, M. \& Fleming, M. (Eds.) (2003). Intercultural Experience and Education. Clevedon, U.K.: Multilingual Matters.

Anderson, P., Lawton, L., Rexeisen, R., \& Hubbard, A. (2006). Short-term study abroad and intercultural sensitivity: A pilot study. International Journal of Intercultural Relations, 30, 457-469.

Bazeley, P. (2007). Qualitative Data Analysis with NVivo. London: SAGE. Bennett, J. M. (2009). Cultivating intercultural competence: A Process Perspective. In D. Deardorff (Ed.). The SAGE Handbook of Intercultural Competence (pp. 121-140). Thousand Oaks, CA: SAGE.

Bennett, J., \& Bennett, M. (2004). Developing intercultural sensitivity: An integrative approach to global and domestic diversity. In D. Landis, J. Bennett \& M. Bennett (Eds.), Handbook of Intercultural Training ( $3^{\text {rd }}$ ed.) (pp. 145-167). Thousand Oaks, CA: SAGE.

Bennett, J., Bennett, M., \& Allen, W. (2003). Developing intercultural competence in the language classroom. In D. Lange, \& M. Paige (Eds.), Culture as the Core: Perspectives on Culture in Second Language Learning (pp. 237-270). Greenwich, CT: Information Age Publishing.

Bennett, M. (1993). Towards ethnorelativism: A developmental model of intercultural sensitivity. In R. M. Paige (Ed.), Education for the Intercultural Experience (pp. 21-71). Yarmouth, ME: Intercultural Press.

Bennett, M. (1997). How not to be a fluent fool: Understanding the cultural dimensions of language. In A. E. Fantini (Vol. ed.), \& J. C. Richards (Series ed.), New Ways in Teaching Culture. New Ways in TESOL Series II: Innovative Classroom Techniques (pp. 16-21). Alexandria, VA: TESOL.

Byram, M. (1997). Teaching and Assessing Intercultural Communicative Competence. Clevedon, U.K.: Multilingual Matters. 
Byram (2008). From Foreign Language Education to Education for Intercultural Citizenship: Essays and Reflections. Clevedon, U.K.: Multilingual Matters.

Byram, M., Gribkova, B. \& Starkey, H. (2002). Developing the Intercultural Dimension in Language Teaching: A Practical Introduction for Teachers. Strasbourg, France: Council of Europe Publishing.

Charmaz, K. (2006). Constructing Grounded Theory: A Practical Guide Through Qualitative Analysis. London: SAGE.

Deardorff, D. K. (2008). Intercultural competence: A definition, model, and implications for education abroad. In V. Savicki (Ed.). Developing Intercultural Competence and Transformation: Theory, Research, and Application in International Education (pp. 32-52). Sterling. VA: Stylus Publishing Inc.

Ditto, P.H., \& Lopez, D.F. (1992). Motivated skepticism: Use of differential decision criteria for preferred and nonpreferred conclusions. Journal of Personality and Social Psychology, 91, 1-15.

Donnelly-Smith, L. (2009). Global learning through short-term study abroad. Peer Review. 11 (4), 12-15.

Durocher, D. O. (2007). Teaching sensitivity to cultural difference in the first-year foreign language classroom. Foreign Language Annals, 40 (1), 143-160.

Engle, L., \& Engle, J. (2004). Assessing language acquisition and intercultural sensitivity development in relation to study abroad program design. Frontiers; The Interdisciplinary Journal of Study Abroad, X, 219-236.

Fischer, P., Greitemeyer, T., \& Frey, D. (2007). Ego depletion and positive illusions: Does the construction of positivity require regulatory resources? Personal and Social Psychology Bulletin, 33 (9), 1306-1321.

Grbich, C. (2007). Qualitative Data Analysis. London: SAGE.

Guilherme, M. (2002). Critical Citizens for an Intercultural World: Foreign Language Education as Cultural Politics. Clevedon, U.K.: Multilingual Matters.

Hammer, M. (2009). The Intercultural Development Inventory: An approach for assessing and building intercultural competence. In M. A. Moodian (Ed.). Contemporary Leadership and Intercultural Competence: Exploring the Cross-Cultural Dynamics within Organizations (pp. 203217). Thousand Oaks, CA: SAGE.

Hammer, M., \& Bennett, M. (2002). The Intercultural Development Inventory: Manual. Portland, OR: Intercultural Communication Institute. 
Hammer, M., Bennett, M., \& Wiseman, R. (2003). Measuring intercultural sensitivity: The intercultural development inventory. International Journal of Intercultural Relations, 27 (3), 421-443.

Institute of International Education (2009). Open doors 2009: U.S. students studying abroad. Washington, DC: Institute of International Education. Intercultural Communication Institute (2004). The Developmental Model of Intercultural Sensitivity. Retrieved from http://www.intercultural.org. Jackson, J. (2006). Ethnographic preparation for short-term study and residence in the target culture. The International Journal of Intercultural Relations, 30 (1), 77-98.

Jackson, J. (2008). Language, Identity, and Study Abroad: Sociocultural Perspectives. London: Equinox.

Jackson, J. (2010). Intercultural Journeys: From Study to Residence Abroad. Basingstoke, Hampshire, U.K.: Palgrave Macmillan.

Kim, Y.Y. (2001). Becoming Intercultural: An Integrative Theory of Communication and Cross-cultural Adaptation. Thousand Oaks, CA, USA: SAGE.

Kim, Y.Y. (2005). Adapting to a new culture: An integrative communication theory. In W. Gudykunst (Ed.), Theorizing about Intercultural Communication (pp. 375-400). Thousand Oaks, CA: SAGE. Kramsch, C.J. (1998). The privilege of the intercultural speaker. In M. Byram \& M. Fleming (Eds.). Language Learning in Intercultural Perspective: Approaches through Drama and Ethnography (pp. 16-31). Cambridge: Cambridge University Press.

Kruger, J. (1999). Lake Wobegon be gone! The 'below-average effect' and the egocentric nature of comparative ability judgments. Journal of Personality and Social Psychology, 77 (2), 221-232.

Kruger, J., \& Dunning, D. (1999). Unskilled and unaware of it: How difficulties in recognizing one's own incompetence lead to inflated selfassessments. Journal of Personality and Social Psychology, 77 (6), 11211134.

Kunda, Z. (1990). The case for motivated reasoning. Psychological Bulletin, 108 (3), 480-498.

Landis, D., Bennett, J., \& Bennett, M. (Eds.). (2004). Handbook of Intercultural Training. ( $3^{\text {rd }}$ ed.). Thousand Oaks, CA: SAGE.

Medina, A. (2008). Intercultural Sensitivity Development in Study Abroad: Is Duration a Decisive Element in Cultural Learning Outcomes? Saarbrücken Germany: Verlag. 
Paige, R.M., Cohen, A., Kappler, B., Chi, J. \& Lassegard, J. P. (2006). Maximizing Study Abroad: A Student's Guide to Strategies for Language and Culture Learning and Use. $2^{\text {nd }} E d$. Minneapolis, MN: University of Minnesota.

Paige, R.M., Jacobs-Cassuto, M., Yershova, Y.A., \& DeJaeghere, J. (2003). Assessing intercultural sensitivity: An empirical analysis of the Hammer and Bennett Intercultural Development Inventory. International Journal of Intercultural Relations, 27 (4), 467-486.

Park, M. (2006). A relational study of intercultural sensitivity with linguistic competence in English-as-a-Foreign-language (EFL) pre-service teachers in Korea. Unpublished Ph.D. thesis. The University of Mississippi.

Pavlenko, A., \& Lantolf, J. (2000). Second language learning as participation and the (re)construction of selves. In J. Lantolf (Ed.), Sociocultural Theory and Second Language Learning (pp. 155-177). Oxford: Oxford University Press.

Richards, L. (2009). Handling Qualitative Data. $2^{\text {nd }}$. Ed. Thousand Oaks, CA: SAGE.

Spencer, S. \& Tuma, K. (Eds.). (2008). The Guide to Successful Short-term Programs Abroad. $2^{\text {nd }}$ ed. Washington, D.C.: NAFSA: Association of International Educators.

Taylor, S. \& Brown, J. (1988). Illusion and well-being: A social psychological perspective on mental health. Psychological Bulletin, 103, 193-210.

Taylor, S., \& Brown, J. (1994). Positive illusions and well-being revisited: Separating fact from fiction. Psychological Bulletin, 116 (1), 21-27. Thomas, J. (1984). Cross-cultural discourse as 'unequal encounter': Towards a pragmatic analysis. Applied Linguistics, 5, 226-235. 


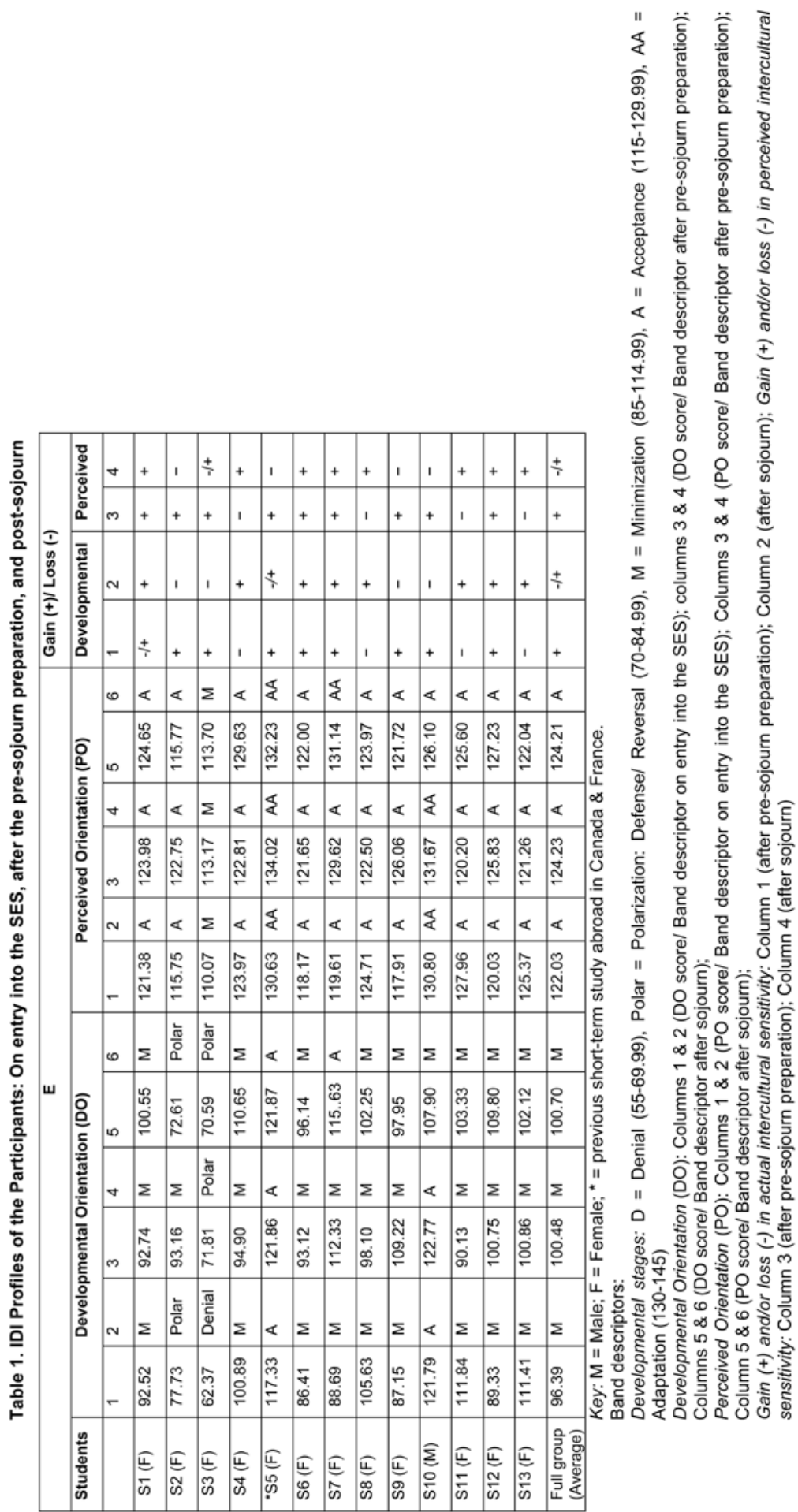

